TITLE:

\title{
Fabrication of wide-band-gap MgxZn1-xO quasi-ternary alloys by molecular-beam epitaxy
}

\author{
$\operatorname{AUTHOR}(\mathrm{S})$ : \\ Tanaka, H; Fujita, S; Fujita, S
}

\section{CITATION:}

Tanaka, H ...[et al]. Fabrication of wide-band-gap MgxZn1-xO quasi-ternary alloys by molecular-beam epitaxy. APPLIED PHYSICS LETTERS 2005, 86(19): 192911.

\section{ISSUE DATE:}

2005-05-09

URL:

http://hdl.handle.net/2433/39673

\section{RIGHT:}

Copyright 2005 American Institute of Physics. This article may be downloaded for personal use only. Any other use requires prior permission of the author and the American Institute of Physics. 


\title{
Fabrication of wide-band-gap $\mathrm{Mg}_{x} \mathrm{Zn}_{1-x} \mathrm{O}$ quasi-ternary alloys by molecular-beam epitaxy
}

\author{
Hiroshi Tanaka and Shigeo Fujita \\ Department of Electronic Science and Engineering, Kyoto University, Kyodai-Katsura, Nishikyo-ku, \\ Kyoto 615-8510, Japan \\ Shizuo Fujita ${ }^{\text {a) }}$ \\ International Innovation Center, Kyoto University, Katsura Int'tech Center Rm.205, Kyodai-Katsura, \\ Nishikyo-ku, Kyoto 615-8510, Japan
}

(Received 20 December 2004; accepted 21 March 2005; published online 6 May 2005)

\begin{abstract}
A series of wurtzite $\mathrm{MgZnO}$ quasi-ternary alloys, which consist of wurtzite $\mathrm{MgO} / \mathrm{ZnO}$ superlattices, were grown by molecular-beam epitaxy on sapphire substrates. By changing the thicknesses of $\mathrm{ZnO}$ layers and/or of $\mathrm{MgO}$ layers of the superlattice, the band-gap energy was artificially tuned from 3.30 to $4.65 \mathrm{eV}$. The highest band gap, consequently realized by the quasi-ternary alloy, was larger than that of the single $\mathrm{MgZnO}$ layer, we have ever reported, keeping the wurtzite structure. The band gap of quasi-ternary alloys was well analyzed by the Kronig-Penny model supposing the effective masses of wurtzite $\mathrm{MgO}$ as $0.30 m_{0}$ and $(1-2) m_{0}$ for electrons and holes, respectively.
\end{abstract}

(C) 2005 American Institute of Physics. [DOI: 10.1063/1.1923762]

Zinc oxide $(\mathrm{ZnO})$ and related semiconductor crystals have recently attracted increasing interest toward application to ultraviolet (UV) light emitters, ${ }^{1}$ deep UV sensors, ${ }^{2}$ transparent thin-film transitors, ${ }^{3}$ multifunctional integrated circuits, and so on. For the actual device applications, the bandgap engineering is one of the indispensable issues to be achieved, for example, the alloying with magnesium oxide $(\mathrm{MgO})$ to make $\mathrm{MgZnO}$ can increase the band-gap energy from $3.3 \mathrm{eV}$ for wurtzite $\mathrm{ZnO}$ to $7.8 \mathrm{eV}$ for rocksolt $\mathrm{MgO}$ (Ref. 4) with fairly small mismatching (0.1\%) (Ref. 5) in bond lengths of $\mathrm{ZnO}$ and $\mathrm{MgO}$.

However, in a lot of research on the growth of $\mathrm{MgZnO}$, one encounters the fatal problem of phase separation, ${ }^{6,7}$ where a segregated nanophase embedded in the host matrix is precipitated. ${ }^{8}$ Accordingly, in the previous works, the maximum band gap extended from $\mathrm{ZnO}$ and achieved with wurtzite $\mathrm{MgZnO}$ has been limited to $3.9 \mathrm{eV} .{ }^{6,7}$ For that problem, we have recently proposed the use of a high-quality $\mathrm{ZnO}$ buffer layer to firmly fix the crystal structure of the layer successively grown on it to wurtzite and, as a result, the growth of single-phase wurtzite $\mathrm{Mg}_{x} \mathrm{Zn}_{1-x} \mathrm{O}$ with magnesium $(\mathrm{Mg})$ content $x$ of as high as 0.51 with band-gap energy of $4.45 \mathrm{eV}$ has been reported. ${ }^{9}$

In the present letter, the attempt to realize the wider band gap, as well as to easily and widely control the band gap, is reported by the use of $\mathrm{MgO} / \mathrm{ZnO}$ superlattice quasi-ternary alloys, instead of $\mathrm{MgZnO}$ ternary alloys. A quasi-ternary alloy of $\mathrm{AX}$ and $\mathrm{BX}$ layers ( $\mathrm{A}$ and $\mathrm{B}$ are cation, $\mathrm{X}$ is anion) or of $\mathrm{YC}$ and $\mathrm{YD}$ layers ( $\mathrm{Y}$ is cation, $\mathrm{C}$ and $\mathrm{D}$ are cation) consists of $\mathrm{AX} / \mathrm{BX}$ or $\mathrm{YC} / \mathrm{YD}$ superlattices, which is recognized equivalent to a ternary alloy $\mathrm{A}_{x} \mathrm{~B}_{1-x} \mathrm{X}$ or $\mathrm{YC}_{x} \mathrm{D}_{1-x}$ from the view point of the band-gap energy. One of the advantages of quasi-alloys ${ }^{10-16}$ is that their band gap can be tuned by the thicknesses of the constituent binary layers, allowing easy modulation of band gap energy along the growth direction. Further, one may not encounter any problem arising from

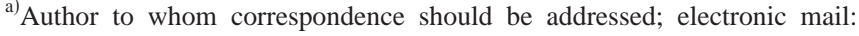
fujita@iic.kyoto-u.ac.jp alloying, such as phase separation or alloy scattering. Therefore, by the $\mathrm{MgO} / \mathrm{ZnO}$ superlattice quasi-ternary alloy, one may expect the possibility of extending the band-gap energy over $4.45 \mathrm{eV}$ attained by the single $\mathrm{MgZnO}$ layer. Actually, in the present work, we report the quasi-ternary alloy with its band gap of as large as $4.65 \mathrm{eV}$, which is wide band gap realized with a wurtzite $\mathrm{ZnO}$-based semiconductor.

The motivation for the $\mathrm{MgO} / \mathrm{ZnO}$ superlattice quasiternary alloys is supported by the fact that a thin wurtzite $\mathrm{MgO}$ layer can be grown on a wurtzite $\mathrm{ZnO}$ layer. We employed molecular beam epitaxy (MBE) for the growth on

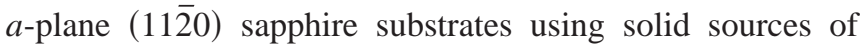
zinc $(\mathrm{Zn})$ and magnesium $(\mathrm{Mg})$ together with rf radical oxygen source. Details of the growth system and process have been published elsewhere. ${ }^{19}$ Following the cleaning of substrate surface in the $\mathrm{MBE}$ growth chamber, a $\mathrm{ZnO}$ buffer layer was grown at $390{ }^{\circ} \mathrm{C}$, then it was annealed at $710^{\circ} \mathrm{C}$ without irradiation of any source for the improvement of both the crystallinity and surface morphology. Figure 1 shows the reflection high-energy reflection (RHEED) pattern when a $\mathrm{MgO}$ layer is grown on the $\mathrm{ZnO}$ buffer layer at $490{ }^{\circ} \mathrm{C}$, where the growth rate of $\mathrm{MgO}$ was about $4 \mathrm{~nm} / \mathrm{min}$. The oxygen flow rate and $\mathrm{rf}$ power of the radical cell were kept at $0.30 \mathrm{sccm}$ and $400 \mathrm{~W}$, respectively. The

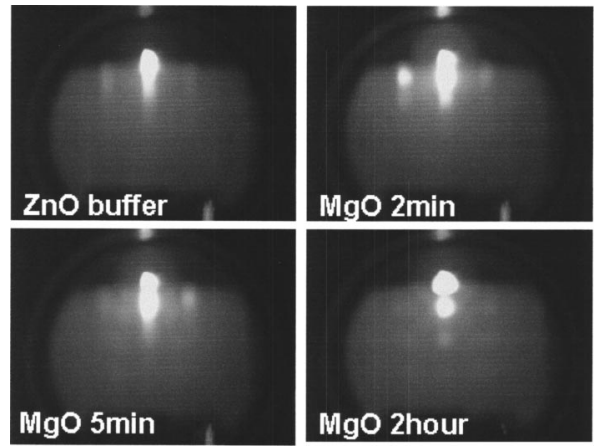

FIG. 1. Variation of RHEED patterns of $\mathrm{MgO}$ on a $\mathrm{ZnO}$ buffer layer with the growth time. The growth rate of $\mathrm{MgO}$ was about $4 \mathrm{~nm} / \mathrm{min}$. 


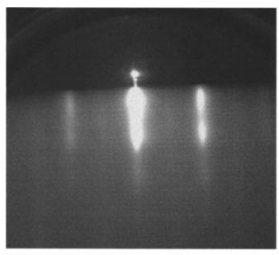

$5 \mathrm{~min}$ $(\sim 20 \mathrm{~nm})$

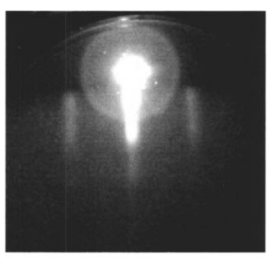

$20 \mathrm{~min}$ $(\sim 80 \mathrm{~nm})$
FIG. 2. RHEED patterns of a MgZnO quasi-ternary alloy during the growth, that is, $5 \mathrm{~min}$ (about $20 \mathrm{~nm}$ ) and $20 \mathrm{~min}$ (about $80 \mathrm{~nm}$ ) after starting the growth, showing wurtzite structure throughout the growth.

beam pressures of $\mathrm{Zn}$ and $\mathrm{Mg}$ were at about $2 \times 10^{-6}$ Torr and $2 \times 10^{-7}$ Torr, respectively.

As shown in Fig. 1, after starting the growth of $\mathrm{MgO}$ on $\mathrm{ZnO}$, no significant change in the RHEED pattern was found until the growth time of $2 \mathrm{~min}$ (about $8 \mathrm{~nm}$ in thickness). However, as the growth proceeded, it changed the spotty one, suggesting severe degradation and/or incorporation of the rocksalt structure. This implies that the $\mathrm{MgO}$ on $\mathrm{ZnO}$ takes a wurtzite structure until its thickness exceeds a critical value.

Therefore, it could be possible to fabricate $\mathrm{MgO} / \mathrm{ZnO}$ superlattice quasi-ternary alloys, keeping the wurtzite structure, by limiting the thickness of the $\mathrm{MgO}$ below the critical one, for example, $<10 \mathrm{~nm}$. Figure 2 shows the RHEED patterns during the growth of a $\mathrm{MgO} / \mathrm{ZnO}$ superlattice. The streaky pattern, suggesting wurtzite structure, was continuously seen throughout the growth.

The $\mathrm{MgO} / \mathrm{ZnO}$ superlattice structure was characterized by transmission electron microscopy (TEM). Figure 3 shows the dark-field TEM image of one of the superlattices. The striped structure of the superlattice of 60 periods, as we designed, with the thickness of each constituent layer of about $1 \mathrm{~nm}$ was confirmed. This implies that $\mathrm{Zn}$ and $\mathrm{Mg}$ atoms hardly diffuse each other to form the short-period superlattice acting as a quasi-ternary alloy. However, in Fig. 3, many dislocations and thickness fluctuation of the constituent layers are present. It may be due to the unoptimized structure design and growth conditions, at present.

The band gap of the MgZnO quasi-ternary alloys was determined from the transmission spectra of the films. An example of the spectrum, in comparison with that of a single $\mathrm{MgZnO}$ layer, whose thickness is about $650 \mathrm{~nm}$, is shown in Fig. 4. Calculating the band gaps from the spectra, it is shown that the arbitral tuning of the band-gap energies from 3.30 to $4.65 \mathrm{eV}$ is achieved by changing the thicknesses of

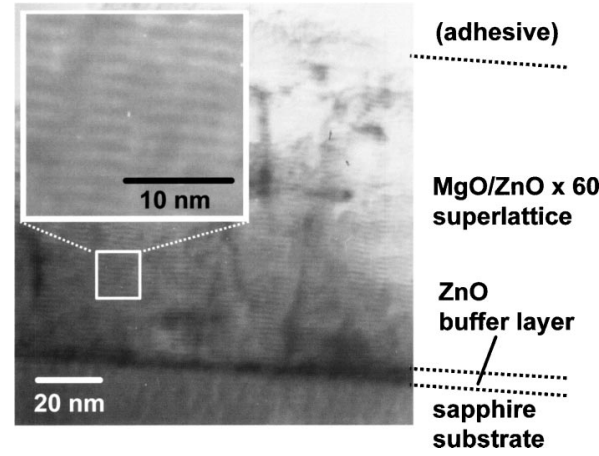

FIG. 3. Cross-sectional TEM images of a MgZnO quasi-ternary alloy with a

highest band-gap energy of $4.45 \mathrm{eV}$.
Downloaded 30 May 2007 to 130.54 .110 .22 . Redistribution subject to AlP license or copyright, see ht

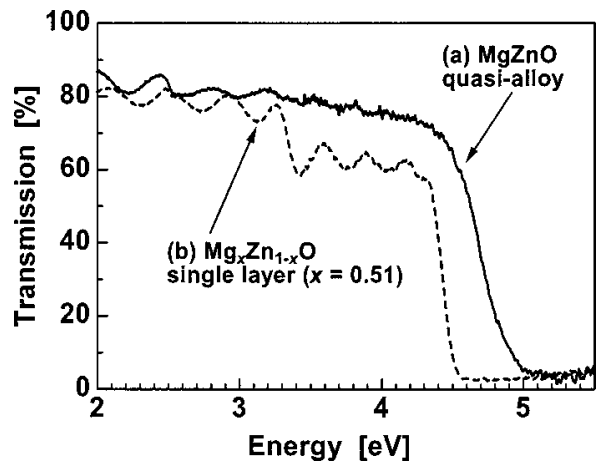

FIG. 4. An example of optical transmission spectrum of a $\mathrm{MgZnO}$ quasiternary alloy with wide band gap, in comparison to that of the $\mathrm{MgZnO}$ single layer of wurtzite structure and possessing the highest band-gap energy of $4.45 \mathrm{eV}$

$\mathrm{ZnO}$ and $\mathrm{MgO}$ layers. The maximum band gap attained was $4.65 \mathrm{eV}$, which is higher than our previous achievement with a wurtzite $\mathrm{Mg}_{0.51} \mathrm{Zn}_{0.49} \mathrm{O}$ single layer. ${ }^{9}$ It should be noted that in Fig. 4, the spectra near the absorption edges of $\mathrm{MgZnO}$ quasi-ternary alloys are not steep in comparison with the $\mathrm{MgZnO}$ single layers. One of the reasons may be the fluctuation of the layer thicknesses, as suggested from the TEM result shown in Fig. 3.

The x-ray diffraction (XRD) $\theta-2 \theta$ spectra of the quasiternary alloys and the $\mathrm{MgZnO}$ single layer are depicted in Fig. 5. For the quasi-ternary alloys with the band gap 3.30 to $4.65 \mathrm{eV}$, only the peaks similar to the (0002) peak from the wurtzite $\mathrm{MgZnO}$ were observed, suggesting that the $\mathrm{MgZnO}$ quasi-ternary alloys keep the wurtzite structure. The peak position slightly shifts to a higher degree with the increase of the average $\mathrm{Mg}$ content in the quasi-ternary alloys.

Then, attempts will be given to analyze the band gap energy values, obtained from the optical transmission measurement, by the theoretical calculation based on the KronigPenny model. As a fundamental parameter for the calculation, the valence-band offset at the $\mathrm{MgO} / \mathrm{ZnO}$ interface must be determined. Ultraviolet photoelectron spectroscopy (UPS) is a useful tool for this purpose, but the clear signal was not obtained from the wurtzite $\mathrm{MgO} / \mathrm{ZnO}$ structure because the $\mathrm{MgO}$ layer was too thin. Therefore, we prepared the series of $\mathrm{Mg}_{x} \mathrm{Zn}_{1-x} \mathrm{O}$ single layers with $x$ of $0,0.20$, and 0.40 , and

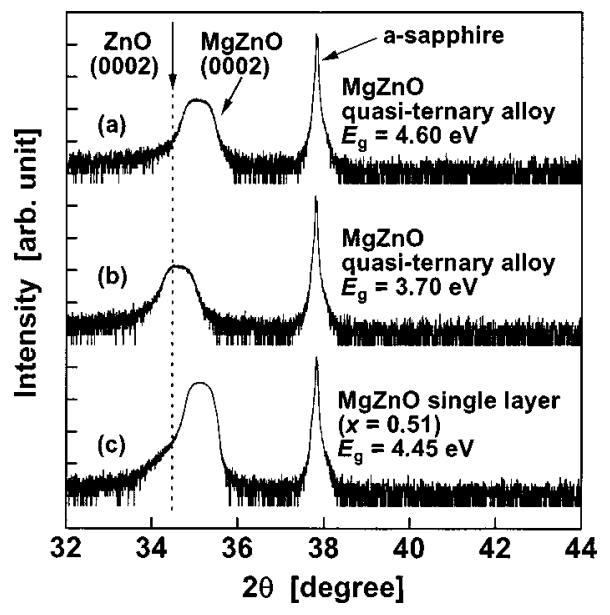

FIG. 5. XRD $\theta-2 \theta$ spectra of $\mathrm{MgZnO}$ quasi-ternary alloys, in comparison to that of the $\mathrm{MgZnO}$ single layer of wurtzite structure and possessing the highest band-gap energy of $4.45 \mathrm{eV}$. ://apl.aip.org/apl/copyright.jsp 
TABLE I. Structures of $\mathrm{MgO} / \mathrm{ZnO}$ superlattices and their band gaps determined from optical transmission spectra. The theoretical values of the band gaps calculated by using the Kronig-Penny model under the assumption of the band offset at $\mathrm{MgO} / \mathrm{ZnO}$ as $1.22 \mathrm{eV}$ and the effective masses of wurtzite $\mathrm{MgO}$ as $0.30 m_{0}$ for electrons and $(1-2) m_{0}$ for holes are also shown in the table for comparison.

\begin{tabular}{cccc}
\hline \hline $\mathrm{MgO}(\mathrm{nm})$ & $\mathrm{ZnO}(\mathrm{nm})$ & $\begin{array}{c}\text { Bandgap (eV) } \\
\text { (measured) }\end{array}$ & $\begin{array}{c}\text { Bandgap (eV) } \\
\text { (calculated) }\end{array}$ \\
\hline 0.20 & 0.20 & 3.65 & 3.45 \\
0.50 & 0.50 & 3.60 & 3.66 \\
0.90 & 0.90 & 3.50 & 3.57 \\
1.0 & 0.27 & 4.15 & 4.18 \\
1.5 & 0.27 & 4.60 & 4.63 \\
4.0 & 0.90 & 4.60 & 4.63 \\
6.0 & 1.3 & 3.70 & 3.69 \\
\hline \hline
\end{tabular}

they are subjected to the UPS measurement. The result gives the energy position of valence-band maximum as a function of $x$, and by extrapolating the results to $x=1$, the valenceband maximum of wurtzite $\mathrm{MgO}$ was estimated. Comparing the values hence obtained, the band offset at $\mathrm{MgO} / \mathrm{ZnO}$ interface was estimated to be $1.22 \mathrm{eV}$. On the other hand, as a result of tight-binding approach proposed by Harrison, ${ }^{11,12}$ the value of the valence-band offset was calculated to be only $30 \mathrm{meV}$. It is thought that this difference is due to the effects of cation $d$ orbital. These effects were neglected in the references. ${ }^{18,19}$ Wei and Zunger ${ }^{20,21}$ pointed out that $p^{a}-d^{c}$ interaction could not be neglected in compound semiconductors, especially in II-VI compounds. It is thought that the valence-band maximum of $\mathrm{ZnO}$ is shifted upward by the $p$ $-d$ repulsion and it is thought that the estimated valence-band offset value of $1.22 \mathrm{eV}$ from UPS is due to this effect. Then, the conduction-band offset is calculated to be $1.75 \mathrm{eV}$ by taking the band gaps of wurtzite $\mathrm{ZnO}$ and $\mathrm{MgO}$ as $3.37 \mathrm{eV}$ and $6.34 \mathrm{eV}$, respectively. ${ }^{22}$ With the use of above values, the subband energies $E$ were derived by using the KronigPenny model.

It should be noted that the calculation needs the effective masses in $\mathrm{ZnO}$ and $\mathrm{MgO}$. For $\mathrm{ZnO}$, we used $0.30 m_{0}$ and $1.8 m_{0}$ as the effective masses of electrons and holes, ${ }^{23}$ respectively. However, the effective masses of wurtzite $\mathrm{MgO}$ have been ambiguous so far. Therefore, we treated the effective masses of $\mathrm{MgO}$ as fitting parameters and the band gaps of various $\mathrm{MgO} / \mathrm{ZnO}$ superlattice structures have been analyzed by using the above equations. As a result, the theoretical values of the band gaps well coincided with the experimental values in various structure samples, when the effective masses of electrons and holes in wurtzite $\mathrm{MgO}$ were assumed to be $0.30 m_{0}$ and $(1-2) m_{0}$, respectively. Since the critical relationship between band offsets and effective masses is mainly seen for relatively light masses, for example, $<0.5 m_{0}$, the effective mass of holes cannot be ob- tained more accurately than $(1-2) m_{0}$. The results are summarized in Table I.

In summary, we reported the fabrication of wurtzite Mg$\mathrm{ZnO}$ quasi-ternary alloys by applying $\mathrm{MgO} / \mathrm{ZnO}$ shortperiod superlattices. The band gaps were tuned from 3.30 to as large as $4.65 \mathrm{eV}$, which was larger than that achieved by the wurtzite $\mathrm{MgZnO}$ single layer, and were well explained by the Kronig-Penny model using the band offset at $\mathrm{MgO} / \mathrm{ZnO}$ as $1.22 \mathrm{eV}$ and the effective masses of wurtzite $\mathrm{MgO}$ as $0.30 m_{0}$ for electrons and (1-2) $m_{0}$ for holes. Using these $\mathrm{MgZnO}$ quasi-ternary alloys, it is expected to become easier to design the various and unique $\mathrm{ZnO}$-based semiconductor devices.

The authors wish to thank Y. Yamashita for the UPS measurement. This work was partly supported by Kochi Prefecture Collaboration of Regional Entities for the Advancement of Technological Excellence (CREATE), Japan Science and Technology Agency (JST).

${ }^{1}$ X.-L. Guo, J.-H. Choi, H. Tabata, and T. Kawai, Jpn. J. Appl. Phys., Part 2 40, L177 (2001).

${ }^{2}$ M. Razeghi, Proc. IEEE 90, 1006 (2002).

${ }^{3}$ F. M. Hossain, J. Nishii, S. Takagi, A. Ohtomo, T. Fukumura, H. Fujioka, H. Ohno, H. Koinuma, and M. Kawasaki, J. Appl. Phys. 94, 7768 (2003).

${ }^{4}$ W. Yang, R. D. Vispute, S. Choopun, R. P. Sharma, T. Venkatesan, and H. Shen, Appl. Phys. Lett. 78, 2787 (2001).

${ }^{5}$ W. R. L. Lambrecht, S. Limpijumnong, and B. Segall, MRS Internet J. Nitride Semicond. Res. 4S1, G6.8 (2000).

${ }^{6}$ A. Ohtomo, M. Kawasaki, T. Koida, K. Masubuchi, H. Koinuma, Y. Sakurai, Y. Yoshida, T. Yasuda, and Y. Segawa, Appl. Phys. Lett. 72, 2466 (1998).

${ }^{7}$ S. Choopun, R. D. Vispute, W. Yang, R. P. Sharma, T. Venkatesan, and H. Shen, Appl. Phys. Lett. 80, 1529 (2002).

${ }^{8}$ I. Takeuchi, W. Yang, K.-S. Chang, M. Aronova, O. Famodu, S. Choopun, R. D. Vispute, T. Venkatesan, and L. A. Bendersky, Abstract Book of MRS 2nd International Workshop on ZnO, Dayton, USA, 2002, p. 50.

${ }^{9}$ T. Takagi, H. Tanaka, S. Fujita, and S. Fujita, Jpn. J. Appl. Phys., Part 2 42, L401 (2003).

${ }^{10}$ L. Esaki and R. Tu, IBM J. Res. Dev. 14, 1131 (1970).

${ }^{11}$ T. Fukui and H. Saito, Jpn. J. Appl. Phys., Part 2 23, L521 (1984).

${ }^{12}$ K. Doi, H. Asahi, J. H. Kim, K. Asami, and S. Gonda, Jpn. J. Appl. Phys., Part 2 35, L1391 (1996).

${ }^{13}$ T. Takanohashi and M. Ozeki, Jpn. J. Appl. Phys., Part 2 30, L956 (1991).

${ }^{14}$ A. Rubio, J. L. Corkill, and M. L. Cohen, Phys. Rev. B 49, 1952 (1994).

${ }^{15}$ T. Abe, H. Ishikura, Y. Saomoto, K. Goto, K. Masuda, T. Shirai, H. Yamada, S. Kuroda, H. Kasada, and K. Ando, J. Cryst. Growth 214, 492 (2000).

${ }^{16}$ A. W. Jia, M. Kobayashi, and A. Yoshikawa, J. Electron. Mater. 24, 117 (1995).

${ }^{17}$ K. Sakurai, M. Kanehiro, K. Nakahara, T. Tanabe, S. Fujita, and S. Fujita, J. Cryst. Growth 209, 522 (2000).

${ }^{18}$ W. A. Harrison, J. Vac. Sci. Technol. 14, 1016 (1977).

${ }^{19}$ W. A. Harrison, in Electronic Structure and the Properties of Solids (W. H. Freeman and Company, San Francisco, 1980).

${ }^{20}$ S. H. Wei and A. Zunger, Phys. Rev. Lett. 59, 144 (1987)

${ }^{21}$ S. H. Wei and A. Zunger, Phys. Rev. B 37, 8958 (1988).

${ }^{22}$ S. Limpijumnong and W. R. L. Lambercht, Phys. Rev. B 63, 104103 (2001).

${ }^{23}$ M. Kawasaki and A. Ohtomo, Kotai Butsuri 33, 59 (1998) [in Japanese]. 